\title{
Karakteristik Guru dalam Tradisi Pendidikan Nahdlatul Wathan, Lombok
}

\author{
Prosmala Hadisaputra ${ }^{* 1}$, Ahmad bin Yussuf ${ }^{2}$, \\ Tengku Sarina Aini binti Tengku Kasim ${ }^{3}$
}

\author{
${ }^{1}$ Mahasiswa Ph.D, Program Pendidikan Islam, Akademi Pengajian Islam, \\ Universiti Malaya, Kuala Lumpur, Malaysia \\ ${ }^{2,3}$ Pensyarah, Program Pendidikan Islam, Akademi Pengajian Islam, \\ Universiti Malaya, Kuala Lumpur, Malaysia \\ 3e-mail: ${ }^{3}$ prossayangamalia@gmail.com, ${ }^{2}$ amdysf@um.edu.my \\ 'tgsarina@um.edu.my
}

\begin{abstract}
This article discusses the characteristics of teacher who teaches Islamic sciences in the perspective of the Nahdlatul Wathan educational tradition, comprehensively. On the other hand, this article is one form of response to the moral degradation of teachers that have recently been rife, especially in Indonesia. This article is the result of qualitative research with a literature approach. Primary data are the books of Tuan Guru Kiai Haji Muhammad Zainuddin Abdul Madjid (Sheikh), which include Wasiat Renungan Masa (Book), Batu Ngompal (Book), the struggle song of Nahdlatul Wathan, and the recording of Sheikh's speech during his lifetime. Secondary data consists of scientific journals and relevant research results, as well as Islamic education books, Sufism, tafsir and hadith. Data was collected offline and online, then analyzed by using the NVivo 12 Plus software. This study shows that nine characteristics must be possessed by religious teachers who teach in the Nahdlatul Wathan madrasas/pesantrean (Islamic boarding school), namely: murshīd, sincere, obedient, mandate, behave as the teacher's morals, have a clear pedigree (silsilah/sanad), wise and polite in speaking, competent, and straight (istiqamah). This study concludes that the characteristics of the teacher mentioned in the will of the Sheikh are based on the results of contemplation (tafakkur), empirical experience (tajribah), and extensive knowledge.
\end{abstract}

Keywords —Characteristics, Educational Tradition, Nahdlatul Wathan, Teacher.

Abstrak: Artikel ini membahas karakteristik guru agama (Islam) dalam perspektif tradisi pendidikan Nahdlatul Wathan, secara komphensif. Di sisi lain, artikel ini merupakan salah satu bentuk respon dari degradasi moral guru yang akhir-akhir ini marak terjadi, khususnya di Indonesia. Artikel ini merupakan hasil penelitian dengan pendekatan library research. Data primer adalah karya tulis Tuan Guru Kiai Haji Muhammad Zainuddin Abdul Madjid (Sheikh), yang meliputi kitab Wasiat Renungan Masa, Kitab Batu Ngompal, lagu perjuangan Nahdlatul Wathan, dan rekaman pidato Sheikh semasa hidupnya. Data sekunder terdiri dari jurnal-jurnal ilmiah dan hasil-hasil penelitian yang relevan, serta buku-buku pendidikan Islam, tasawuf, tafsir dan hadith. Data dikumpulkan secara offline dan online, kemudian dianalisis menggunakan software NVivo 12 Plus. Penelitian ini menunjukkan bahwa ada sembilan karakteristik yang harus dimiliki oleh guru agama yang mengajar di madrasah/pesantren Nahdlatul Wathan, yaitu: murshid, ikhlas, taat, amanat, berakhlak guru, memiliki silsilah keilmuan yang jelas, bijaksana dan santun dalam bertutur kata, kompeten, dan istiqamah. Penelitian ini menyimpulkan

Jurnal At-Tafkir: Volume 13 Nomor 1 Tahun 2020

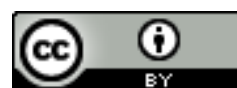

This work is licensed under a Creative Commons Attribution 4.0 International License 


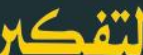

bahwa karakteristik-karakteristik guru yang disebutkan di dalam wasiat Sheikh didasari oleh hasil perenungan (tafakkur), pengalaman empiris (tajrïbah), dan ilmu yang luas.

Kata kunci- Guru, Karakteristik, Nahdlatul Wathan, Tradisi Pendidikan.

\section{PENDAHULUAN}

Guru adalah pendidik professional. Ia telah bersedia dengan penuh kerelaan untuk menerima sebagian amanat pendidikan yang dibebankan oleh orangtua. Hal itu menunjukkan bahwa tidak sembarang orang dapat menjadi guru (Daradjat, 2016). Oleh karena itu, guru sangat dihormati oleh masyarakat. Di india, guru dianggap orang suci. Di Jepang guru disebut sensei yang berarti dituakan. Dalam istilah yang sangat umum, guru adalah pengajar, sehingga dalam tradisi barat, di Inggris misalnya menyebut guru dengan istilah teacher (Daradjat, 2016). Namun bagaimanapun guru bukan sekadar pengajar, yang hanya mengajar untuk menghabiskan materi, namun guru adalah seorang pendidik baik di dalam maupun di luar sekolah.

Dalam konteks Islam, guru mendapatkan posisi yang utama. Allah mengangkat derajat orang yang berilmu beberapa derajat sebagaimana yang tercantum dalam QS. al-Mujādalah (58): 1l. Guru termasuk dalam kategori yang diangkat derajatnya, karena ia memiliki ilmu pengetahuan ('alīm). Oleh karena itu profesi guru menjadi profesi yang mulia. Kemuliaan yang didapat oleh guru berbanding lurus dengan tanggung jawab yang diemban. Para guru memanggul amanat untuk mendidik siswa, baik secara intelektual, spiritual, maupun moral.

Namun bagaimanapun citra guru yang mulia menjadi tercoreng karena perbuatan buruk dari oknum guru. Sejumlah tindakan kekerasan seksual dan nonseksual terjadi di sekolah/madrasah/pesantren. Ada 17 kasus kekerasan pada anak di lingkungan pendidikan pada priode Januari-Oktober 2019. Jumlah korban mencapai 89 anak. Sebanyak 55 orang di antaranya anak perempuan dan 34 anak laki-laki. 88\% oknum guru dan 22\% oknum kepala sekolah adalah pelaku kekerasan terhadap peserta didiknya. Sebanyak 2 orang (13\%) merupakan guru agama (Diakses 17/02/2019 https://akurat.co/news/id-835557-read-kpai-17-kasuspelecehan-seksual-di-sekolah-didominasi-jenjang-sekolah-dasar ) Di Kota Lhokseumawe, Provinsi Aceh, sebanyak 15 santri sebuah lembaga pendidikan agama diduga menjadi korban pelecehan seksual. Ironisnya, pelaku pelecehan dilakukan oleh oknum pimpinan dayah/pesantren dan guru agama (Diakses 2/18/2020 https://kompas.id/baca/nusantara/2019/07/11/15-santri-di-aceh-jadikorban-pelecehan-seksual/). Di Medan, seorang guru berkelahi dengan sesama guru di dalam kelas, yang disaksikan oleh anak didiknya. (Diakses pada tanggal 2/18/2010 https://www.youtube.com/watch?v=-HkzxhRYaOY).

Fakta-fakta tersebut menunjukkan bahwa degradasi moral tidak hanya terjadi pada peserta didik, namun juga pada guru. Kondisi seperti ini menuntut adanya penguatan konsep tentang karakteristik guru dalam pespektif pendidikan Islam. Guru tidak sekadar datang ke sekolah/madrasah untuk mengajar, namun

Jurnal At-Tafkir: Volume 13 Nomor 1 Tahun 2020

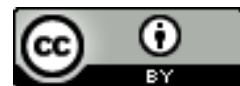

This work is licensed under a Creative Commons Attribution 4.0 International License 
untuk mendidik, membimbing, dan mengayomi. Oleh karena itu, dalam artikel ini akan disajikan karakteristik guru dalam tradisi pendidikan Nahdlatul Wathan.

Nahdlatul Wathan (NW) adalah organisasi masyarakat Islam yang bergerak di bidang pendidikan, sosial, dan dakwah. Nahdlatul Wathan memiliki madrasah tidak kurang dari 1600 buah, yang tersebar di seluruh Indonesia. Organisi terbesar di Nusa Tenggara Barat ini didirikan oleh Tuan Guru Kiai Haji Muhammad Zainuddin Abdul Madjid. Oleh karena itu mendiskusikan tentang Nahdlatul Wathan tidak lepas dari gagasan dan ide dari pendirinya.

Analisis terhadap kajian-kajian terdahulu (table 1) menunjukkan bahwa tema pendidikan mendominasi dalam kajian tentang Nahdaltul Wathan, kemudian tema politik, sosial, dan dakwah (tabel 2 dan gambar 1). Temuan ini menjadi sangat menarik karena tema politik sebagai tema yang paling banyak dikaji menempati urutan kedua setelah pendidikan, sekalipun politik tidak masuk dalam ranah pergerakan Nahdaltul Wathan.

Mula-mula tema diklasifikasikan menjadi tiga area pergerakan NW, namun dalam proses analisis, kata politik muncul menjadi kata yang banyak dibicarakan dalam kajian-kajian terdahulu. Oleh karena itu kami memutuskan utnuk menelusuri setiap jurnal untuk memastikan tema yang dibahas. Kenyataan tersebut dapat dilihat pada gambar word cloud berikut ini:

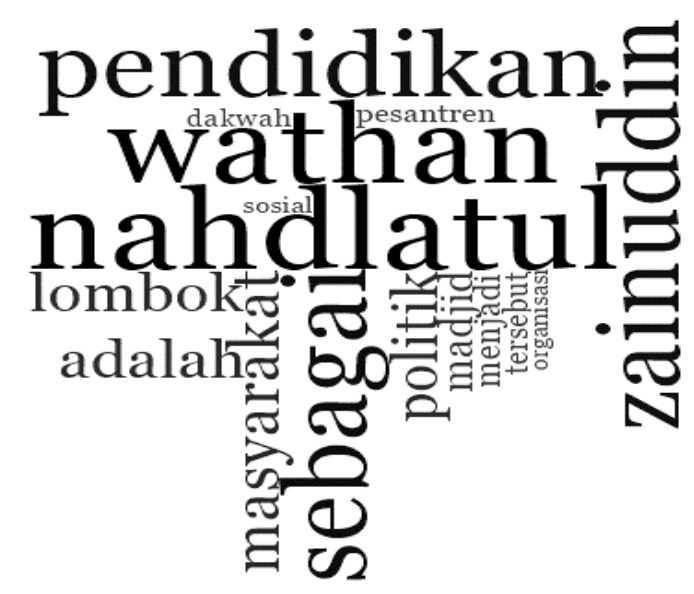

Gambar 1: Tema-Tema dalam Kajian Terdahulu tentang NW dalam sajian Word Cloud (Diolah melalui NVivo 12 Plus) 
Tabel 1: Tema-Tema dalam Kajian-Kajian Terdahulu Tentang NW Versi Google Scholar

Kajian Terdahulu Penulis (Bahasa Indonesia) Pendidikan

Nahdi 2009; Nahdi 2013; Munadi, 2015; Fattah dkk. 2019; Hapizin \& Ihsan, 2017; Samidi \& Suharno, 2018; Isma'il, 2006; Saparuddin, 2017; Usman, 2010; Karmilawati, 2018; Nasip, Wahyuni, \& Nuriadi, 2019;

Politik Fahrurrozi, 2017; Watoni, 2017; Juma'ah, Sulaksono, \& Sarofah, 2017; Hamdi, 2011, 2011, 2015; Abdurrahman, 2014; Ziadi, 2018;

\begin{tabular}{ll}
\hline Sosial & $\begin{array}{l}\text { Jamiluddin, 2018; Parhanuddin, 2012; } \\
\text { Amrullah, 2016; }\end{array}$ \\
\hline Budaya & $\begin{array}{l}\text { Suparman, 2017; Fahrurrozi, 2015; Samima, } \\
\text { 2016; }\end{array}$ \\
\hline Dakwah & Haramain, 2012; Hamdi, 2018; \\
\hline Bahasa & Wijaya, 2013; Wijaya \& Sartini, 2019 \\
\hline Gender & Nasip, 2017 \\
\hline
\end{tabular}

Tabel 2: Word Frequency dalam Kajian Terdahulu Tentang Nahdlatul Wathan Menggunakan NVivo 12 Plus Kata Batasan Frekuensi

$\begin{array}{cc}\text { Jumlah Kata } & \text { Jumlah minimal } \\ \text { yang muncul } & \text { huruf kata yang }\end{array}$
muncul

\begin{tabular}{cccc}
\hline Pendidikan & 16 & 6 & 1864 \\
\hline Politik & 16 & 6 & 1270 \\
\hline Sosial & 16 & 6 & 970 \\
\hline Dakwah & 16 & 6 & 966 \\
\hline
\end{tabular}

Dari paparan di atas disimpulkan bahwa pertama, kajian ini merupakan salah satu bentuk respon secara pemikiran, terhadap degradasi moral guru yang sedang marak terjadi; kedua, berdasarkan analisis terhadap kajian-kajian terdahulu, bahwa fokus kajian pada karakteristik guru dalam tradisi pendidikan Nahdlatul Wathan belum dijumpai; ketiga tujuan kajian ini adalah untuk mengetahui dan memahami karakteristik guru dalam perspektif Nahdlatul Wathan secara komprehensif.

\section{METODE PENELITIAN}

Metode Penelitian memuat lokasi, jenis penelitian, instrumen/alat pengumpul data, dan analisis data. Sumber data dalam kajian ini terdiri dari sumber primer dan sekunder. Sumber primer terdiri dari karya-karya Sheikh yang

Jurnal At-Tafkir: Volume 13 Nomor 1 Tahun 2020

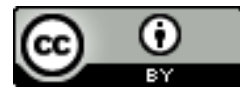

This work is licensed under a Creative Commons Attribution 4.0 International License 
meliputi buku Wasiat Renungan Masa, kitab Batu Ngompal, dan buku kumpulan lagu perjuangan Nahdlatul Wathan. Data sekunder terdiri dari jurnal ilmiah, buku-buku hasil penelitian yang mengkaji tentang Nahdlatul Wathan dan/atau Sheikh, kitab tafsir, hadith dan tasawuf, serta buku-buku pendidikan Islam yang relevan dengan kajian ini.

Pengumpulan data dilakukan secara offline dan online. Data primer dikumpulkan secara offline dari perpustakaan. Data sekunder berupa jurnal ilmiah dikumpulkan secara online melalui google scholar, sedangkan literatur pendukung lainnya berupa kitab-kitab pendidikan, akhlak tasawuf, tafsir dan hadith diunduh melalui website al-waqfeya (www.waqfeya.com). Data online yang telah dikumpulkan di-rename dengan mencantum nama penulis dan tahun terbit. Hal tersebut dilakukan untuk mempermudah pengutipan (citation) pada proses analisis dengan menggunakan software NVivo 12 Plus.

Semua data yang telah dikumpulkan dimasukkan ke dalam software NVivo 12 Plus melalui import data. Setelah di-import, data kemudian analisis secara induktif satu persatu untuk menemukan tema-tema penelitian. Tema-tema yang didapatkan kemudian di-koding melalui fasilitas nodes. Tema-tema yang dibuat dalam nodes ditafsirkan secara elaboratif dengan data-data pendukung (sekunder) berupa buku-buku pendidikan, tasawuf, tafsir, hadith dan jurnal ilmiah yang relevan.

\section{HASIL DAN PEMBAHASAN}

\section{Karakteristik Guru dalam Tradisi Pendidikan NW}

Tuan Guru Kiai Haji Muhammad Zainuddin Abdul Madjid (Sheikh) adalah pendiri Nahdlatul Wathan. Ketokohannya tidak dapat dipisahkan dengan perbincangan mengenai karakteristik guru dalam tradisi pendidikan Nahdlatul Wathan. Sheikh merupakan tokoh sentral, yang merumuskan karakteristik guru dalam tradisi pendidikan NW. Karakteristik guru yang dimaksud dalam pembahasan ini adalah karakteristik guru yang mengajarkan ilmu-ilmu keislaman. Karakteristik tersebut dirumuskan oleh Sheikh berdasarkan hasil perenungan (tafakkur), pengalaman empiris (tajrïbah), dan ilmu yang luas.

Dari analisis terhadap dokumen-dokumen karya Sheikh, penulis berpendapat bahwa Sheikh banyak menuangkan pemikiran-pemikirannya tentang karakteristik guru dalam karyanya yang berjudul Wasiat Renungan Masa, kemudian di lirik lagu perjuangan yang berjudul Sak Tui Jati, dan sejumlah bait dalam Kitab Batu Ngompal. Karakteristik-karakteristik guru tersebut adalah sebagai berikut:

Jurnal At-Tafkir: Volume 13 Nomor 1 Tahun 2020

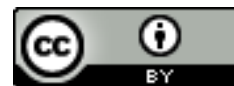

This work is licensed under a Creative Commons Attribution 4.0 International License 


\section{Pertama: Murshīd}

Kata murshid menjadi kata karakteristik utama bagi seorang guru dalam tradisi pendidikan Nahdlatul Wathan. Karakteritik ini disebutkan dalam karya Shekh, Wasiat Renungan Masa, bait ke-97 dan ke 183 (Madjid, 2016).

Dalam Bahasa Arab, kata murshìd berakar dari kata rashida-yarshadu-

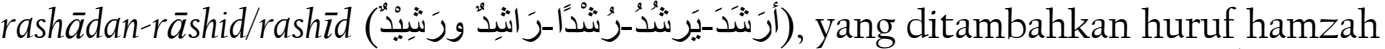

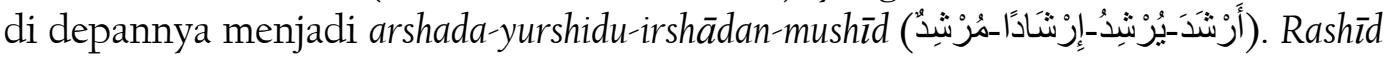
merupakan lawan kata dari al-ḍăl yang berarti yang sesat (Manzūr, n.d.) Kata rashīd dapat dimaknai sebagai orang yang lurus atau orang yang benar. Bahkan AlRashīd, nama Allah dalam Asmā’ al-Ḥusnā, diartikan sebagai Yang Maha Cerdas. Oleh karena itu, jika rashīd dimaknai orang yang lurus, benar, dan cerdas, murshīd berarti orang yang meluruskan, membenarkan, dan mencerdaskan.

Dalam konteks pendidikan, istilah murshīd dapat disepadankan dengan istilah mu'addib, murabbi, mu'allim, mudarris, sheikh dan ustadh. Istilah-istilah tersebut secara sederhana berarti pendidik, pengajar, atau guru. Namun bagaimanapun istilah mu'allim, mudarris, syeikh dan ustadh lebih populer penggunaannya daripada istilah murshìd, muaddib, dan murabbī. Hal tersebut dapat dilacak dari kitab-kitab turāth pendidikan seperti Ta'līm al-Muta'llim fi Turuqi t-Ta'allumi, karya al-Zarnūjī, Tadhkirat al-Sāmi' wa al-Mutakallim fi Adab al-'Ālim wa al-Muta'llim karya Ibnu Jamā'ah, dan Ihyā' 'Ulüm al-Dīn pada bab Ilmu, karya al-Ghazālì.

Dalam kitab Ta'līm al-Muta'allim disebutkan bahwa pengajar disebut istilah ustādh, mudarris, Sheikh, dan 'alim (Al-Zarnūjī, 1981). Ibn Jama'ah (2012) pada bab kedua dalam kitabnya, memperlihatkan kekerapannya menggunakan istilah 'alim (tunggal) dan 'ulama' (jama' dari kata 'alim), untuk menyebut seorang pengajar. Ibnu Jamā'ah juga sangat terlihat memberikan penekanan bahwa guru merupakan pribadi yang berilmu. Di samping istilah 'ālim, Ibn Jama'ah (2012) juga menggunakan istilah sheikh.

al-Ghazali (2005) lebih cenderung menggunakan istilah mu'allim untuk menunjukkan arti guru/pengajar. Di samping itu, al-Ghazālī juga menggunakan istilah al-murshīd. Dari ketiga kitab tersebut, hanya al-Ghazāli yang menggunakan kata murshīd untuk menunjukkan arti guru. Penggunaan kata murshīd dalam Ihyā' Ulüm al-Dīn menunjukkan arah ihya' bukan hanya sebatas kitab pendidikan moral, namun lebih dari itu, Ihyā' merupakan kitab tasawwuf.

Dalam tasawwuf, kata murshīd lazim digunakan untuk menunjukkan kepada pengajar tasawwuf atau tarekat. Murshīd adalah orang yang menunjukkan kepada jalan yang benar sebelum tersesat (al-Jurjāni, n.d.). Secara lahiriah, seorang murshid adalah pemimpin, pembimbing, dan pembina muridmuridnya agar tidak menyimpang dari ajaran-ajaran Islam dan terpelihara dari perbuatan dosa besar dan dosa kecil. Juga, Seorang mursyid harus membimbing murid-muridnya untuk melaksanakan amalan wajib dan sunnah untuk mendekatkan diri kepada Tuhan. Adapun secara rohaniah, seorang murshid

Jurnal At-Tafkir: Volume 13 Nomor 1 Tahun 2020

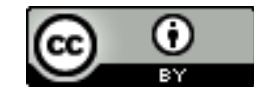

This work is licensed under a Creative Commons Attribution 4.0 International License 
adalah pemimpin kerohanian, yang menuntun dan membawa murid-muridnya menuju rida Tuhan (Sayyi, 2017)

Dalam konteks tradisi pendidikan Nahdlatul Wathan, karakteristik murshid telah merangkul makna sekaligus tangggung jawab seorang mu'addib, murabbī, mu'allim, mudarris, sheikh dan ustādh. Hal tersebut dapat dilihat dalam pandangan Aboebakar Atjeh mengenai sejumlah tanggung jawab yang harus diemban oleh seorang murshid. Atjeh, (1985) mengungkapkan 24 tanggung jawab antara lain: pertama, seorang murshid harus 'alim dan ahli dalam memberikan tuntunan, terutama dalam bidang tauhid dan fikih; kedua, seorang murshid harus 'arif tentang ilmu hati, baik dari segi aspek penyakitnya maupun dari aspek cara pengobatannya; ketiga, seorang murshid harus memiliki sifat pengasih dan penyayang terutama kepada murid-muridnya; keempat, seorang murshid adalah orang yang memiliki kesungguhan untuk menjaga marwahnya, dan seterusnya.

Tradisi pendidikan Nahdlatul Wathan terlihat amat ketat dalam memilih guru. Sheikh seolah-olah menekankan agar guru yang mengajar ilmu-ilmu keislaman memiliki karakter murshīd, layaknya murshīd yang membimbing murid-muridnya dalam jalan kesufian atau tarekat. Menurut penulis, pemilihan guru yang murshīd tidak lepas dari harapan Sheikh dalam kalimat penutup, yang dijadikan ciri khas Nahdlatul Wathan. Kalimat penutup tersebut diucapkan sebelum salam, yaitu Wallāh al-Muwaffiq wa al-Hād̄̄ ilā Sab̄̄l al-Rashād. Harapan Sheikh adalah agar murid-muridnya yang belajar di madrasah-madrasah Nahdlatul Wathan selalu mendapat bimbingan menuju jalan yang benar (Sabīl alRashād). Oleh karena itu, tidak ada yang dapat memberikan bimbingan menuju Sabīl al-Rashād melinkan guru yang memiliki karakter murshid.

\section{Kedua: Ikhlas}

Ikhlas merupakan karakter dasar yang harus dimiliki seorang guru. Ikhlas dalam perkataan dan perbuatan merupakan dasar keimanan ('Ulwān, 1976). Sikap ikhlas dapat dianggap sebagai modal dasar bagi seorang guru untuk dapat mengabdi dan mengajar di pesantren. Sebagai lembaga pendidikan Islam bukan milik pemerintah, pesantren memiliki sumber pendanaan yang terbatas, sekalipun mungkin ada pesantren-pesantren yang kini sudah memiliki sumber pendanaan yang mencukupi. Saat ini, pesantren tidak hanya sebagai lembaga pendidikan Islam yang berfungsi untuk mentransfer ilmu dan budaya Islam, namun pesantren sudah mulai merambah dunia usaha, seperti pertanian, peternakan, jasa travel dan sebagainya. Tujuannya adalah untuk mendukung keberlangsungan pesantren. Namun bagaimanapun, secara umum sumber pendanaan pesantren tidak dapat menyamai lembaga pendidikan milik pemerintah. Oleh karena itu, sikap ikhlas sangat diperlukan bagi guru yang hendak mengajar di pesantren.

Ikhlas dalam bahasa Arab berakar dari kata khulūs yang berarti jernih. Ikhlas menjernihkan hati dari hal-hal yang mengotorinya (al-Bustānī, 1987). alJurjāni, (n.d.) mengemukakan sejumlah definisi ikhlas; pertama, ikhlas berarti keinginan agar perbuatan baik yang dilakukan tidak disaksikan selain Allah; Jurnal At-Tafkir: Volume 13 Nomor 1 Tahun 2020

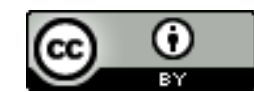

This work is licensed under a Creative Commons Attribution 4.0 International License 
kedua, ikhlas berarti menjernihkan perbuatan dari segala yang dapat mengeruhkannya; dan ketiga, ikhlas adalah penutup di antara hamba dan Tuhannya, sehingga malaikat, setan dan hawa nafsu pun tidak mengetahui.

Ketiga definisi yang dikemukan Al-Jurjānī mengarah kepada definisi ikhlas dalam konteks tasawwuf. al-Qushayri (2001), seorang sufi misalnya, menyatakan bahwa sikap ikhlas berarti mensucikan perilaku dari perhatian manusia. Al-Qushairī juga mengutip perkataan gurunya bahwa ikhlas adalah keinginan untuk mendekatkan diri kepada Allah dengan menaati-Nya, bukan dengan maksud yang lain, seperti melakukan amal perbuatan karena orang lain, atau mencari pujian dan cinta makhluk, dan semua tujuan selain mendekatkan diri kepada Allah.

Sementara itu Sahl, sebagaimana yang dikutip oleh al-Qushayri (2001), mengatakan bahwa tidak seorang pun yang mengetahui perasaan riya' melainkan orang yang ikhlas. Namun bagaimana pun, Dhun Nūn dalam al-Qushayri (2001) mengemukakan tiga tanda ikhlas yang dapat dirasakan oleh orang yang berbuat baik, yaitu; pertama, merasakan hal yang sama antara mendapatkan pujian atau tidak; kedua, melupakan amal kebajikan yang sudah dilakukan, dan ketiga, melupakan pahala yang akan diperoleh di akhirat kelak.

Dalam tradisi pendidikan Nahdlatul Wathan, syarat 'alim tidak cukup untuk menjadi guru di pesantren atau madrasah Nahdlatul Wathan, namun diperlukan sikap ikhlas. Dalam tradisi pendidikan Nahdlatul Wathan, guru yang ikhlas adalah guru yang berjuang tanpa pamrih. Ia tidak mengharapkan imbalan dari manusia, dan hanya berharap rida dari Allah semata. Usman (2015) dalam penelitiannya mengatakan bahwa Sheikh mendefiniskan ikhlas sebagai sikap lahir dan batin yang sama, baik dipuji maupun dicela. Adapun kebalikan dari ikhlas adalah riya. Guru yang riya' adalah guru yang melaksanakan tugasnya dengan pamrih. Ia ingin dilihat berbuat baik, kemudian berharap untuk dipuji dan mendapatkan balasan berupa materi.

\section{Ketiga: Taat}

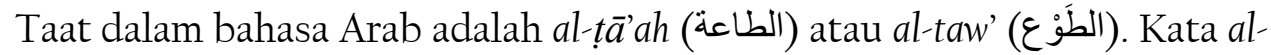
Taw'/ al-Ṭāah merupakan lawan dari kata benci atau terpaksa (Manẓūr, n.d.), yaitu tunduk dan patuh (Munawwir, 1984). al-Jurjāni (n.d.) mendefinisikan taat sebagai persetujuan terhadap suatu perkara secara patuh, tanpa kebencian dan keterpaksaan.

Dalam al-Qur'an, kata Țä'ah dengan ragam derivasinya disebut tidak kurang dari 50 kali. Namun penyebutannya lebih banyak dalam bentuk kata kerja, baik kata kerja yang menunjukkan arti lampau (fi'l al-Māḍī), sekarang atau masa yang akan datang (fi'l al-Muḍāri'), maupun berarti perintah (fi'l al-Amr). Kata taw' (طوع) sendiri disebut sebanyak 4 kali, sedangkan kata ță'ah (طاعة) disebutkan sebanyak 3 kali (al-Bāqī, n.d.).

Dalam konteks Islam, sasaran ketaatan seorang hamba harus sesuai dengan perintah al-Qur'an dalam QS. Al-Nisa' (3:59). Allah memerintahkan hamba-Nya untuk taat kepada Allah, Rasul-Nya, dan ulil amri. Dalam hal ini

Jurnal At-Tafkir: Volume 13 Nomor 1 Tahun 2020

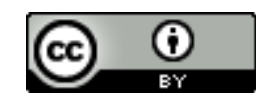

This work is licensed under a Creative Commons Attribution 4.0 International License 
penulis tidak akan membahas mengenai kewajiban taat kepada Allah dan RasulNya, karena kewajiban taat kepada Allah dan Rasul-Nya bersifat mutlak. Oleh karena itu, pada bagian ini penulis akan fokuskan pada diskusi mengenai kewajiban menaati ulul amri.

Para ulama' belum menemukan kata sepakat tentang makna ulul amri yang dimaksud dalam QS. Al-Nisa' (3:59). Ibn Kathīr (1997) dalam tafsirnya mengutip pendapat Ibnu 'Abbas bahwa yang dimaksud dengan ulil amri adalah ahli fikih dan ahli agama. Ibnu Kathīr juga mengutip pendapat Mujāhid, 'Ațā', Hasan al-Bașrī, dan Abū 'Āliyah bahwa ulil amri adalah ulama'. Selanjutnya, Ibnu Kathīr menyimpulkan bahwa ulil amri itu umum, baik umara' maupun 'ulama'. alZamakhsharī (2009) dalam Tafsīr al-Kashshāf menyatakan bahwa yang dimaksudkan dengan ulil amri adalah umara' yang taat kepada Allah dan RasulNya, dan ahli agama yang mengajarkan Islam kemudian menyuruh berbuat baik dan melarang berbuat jahat.

Dalam konteks pendidikan Nahdlatul Wathan, guru yang mengajarkan ilmu agama adalah orang yang taat (Madjid, 2016), baik kepada Allah, Rasul-Nya dan Ulil Amri. Tradisi taat dalam pendidikan Nahdlatul Wathan tampak dari tradisi bai'at yang dilakukan, baik oleh guru maupun pelajar. Dalam teks bai'at dan ikrar, taat kepada Allah dan Rasul-Nya dinyatakan pada nomor pertama yaitu dalam bentuk perjanjian takwa kepada Allah dan Rasul-Nya.

Adapun ketaatan kepada ulil amri, maka itu dinyatakan dalam ikrar nomor dua, tiga, dan empat. Dalam ikrar nomor dua, jama'ah Nahdlatul Wathan termasuk guru, mengikrarkan janji untuk taat kepada Tuan Guru Kiayi Haji Muhammad Zainuddin Abdul Madjid, pendiri Nahdlatul Wathan, kepada orang tua dan guru. Bai'at nomor tiga adalah janji untuk taat kepada ajaran Ahlussunnah wal Jama'ah dan Madhhab Shafi'i. Bai'at nomor empat adalah janji setia kepada Pancasila dan dan Undang-Undang Dasar 1945 (Madjid, 2016). Sikap taat kepada ulil amri dalam tradisi pendidikan Nahdlatul Wathan mencakup sikap taat kepada guru, orangtua, dan negara, karena ketiga ulil amri tersebut merupakan tiga institusi yang mengurus kehidupan manusia. Oleh karena itu, karakteristik guru dalam tradisi pendidikan Nahdlatul Wathan adalah guru yang menaati guru-gurunya.

\section{Keempat: Amanat}

Amanat merupakan lawan dari khianat (Ibn Manzūr, n.d.). Makna tersebut dapat dipahami dari hadith ciri-ciri orang munafik; yaitu berkata dusta, mengingkari janji, dan berkhianat. Ibnu Manzūr dalam menjelaskan makna amanah merujuk sejumlah hadith. Ia mencontohkan bahwa tukang azan adalah orang yang diamananatkan oleh masyarakat. Mereka mempercayai muadhdhin sebagai orang yang bisa menjaga shalat dan puasa masyarakat. Lebih lanjut Ibnu Manzur menjelaskan bahwa sikap amanat dapat diimplemetasikan dalam ketaatan, ibadah, muamalah (seperti wadiah/titipan), kepercayaan, dan keamanaan (Manzūur, n.d.). Mengenai makna amanat, al-Maydāni (1995) mengatakan bahwa amanat berakar dari kata amān (أمان) yang berarti tidak takut.

Jurnal At-Tafkir: Volume 13 Nomor 1 Tahun 2020

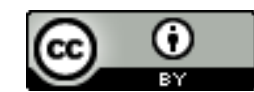

This work is licensed under a Creative Commons Attribution 4.0 International License 
Kata amānah yang berakar dari kata amān menunjukkan bahwa siapapun yang memiliki sikap amanat, maka pemilik hak tidak akan pernah takut kehilangan haknya dan pemilik janji tidak takut janjinya tidak ditepati.

Dalam tradisi pendidikan Nahdlatul Wathan, ikhlas merupakan salah satu karakteristis yang harus dimiliki oleh guru (Madjid, 2016). Ketika seseorang telah diterima menjadi guru di Nahdlatul Wathan, lebih-lebih dia telah menyatakan baiat dan ikrar, maka seketika itu ia mengemban amanat yang harus ditunaikan. Salah satunya adalah bersikap amanat, sesuai karakteristik guru Nahdlatul Wathan.

Dalam konteks belajar mengajar, sikap amanat dapat diimplementasikan melalui sikap-sikap yang menunjukkan tanggung jawabnya sebagai seorang guru. Misalnya ketika guru berada di madrasah/pesantren, maka guru harus menyayangi, membimbing, dan mengayomi para pelajar, karena orangtua mereka telah mengamanatkan pendidikan mereka kepada guru di madrasah/pesantren. Adapun saat berada di luar sekolah, guru menunjukkan sikap amanatnya dengan cara menjaga nama baik insititusi tempat ia mengajar. Terkait dengan urusan administrasi, guru dituntut jujur saat mengisi absensi kehadiran, mengisi jurnal pembelajaran sesuai dengan materi yang diajar, dan memberikan penilaian dengan objektif terhadap hasil belajar siswa.

Sikap amanat yang dimiliki oleh guru dapat memberi pengaruh positif, baik bagi guru maupun siswa. al-Hajjajjī (1977) dalam penelitiannya terhadap pemikiran pendidikan Ibn al-Qayyim mengungkap pengaruh positif sikap amanat. Menurut al-Hajjaji, jika guru dapat menjaga diri dari sikap khianat, ia telah menjadikan agamanya bercahaya, urusannya bermanfaat, jiwanya bersemangat, dan hatinya responsif, serta memberikan pengaruh positif bagi orang lain. Demikian sebaliknya, jika guru berperingai khianat atau kurang amanat, ia mencabut cahaya ilmunya dan menghilangkan pengaruh positif terhadap orang lain.

Senada dengan dengan pendapat al-Hajjājīi, Ali (1977) juga mengungkap efek positif dari sikap amanat. Menurut 'Alī, sikap amanat adalah sebagian dari nilai-nilai yang digalakkan dan ditekankan oleh pendidikan Islam. Sikap amanat merupakan penyangga masyarakat, fondasi kepercayaan (trust) dan pergaulan dalam masyarakat. Sikap amanat dapat menjadi daya dukung kepribadian seseorang, sehingga ia mendapatkan tempat yang diperhitungkan di masyarakat. Seseorang yang amanat akan diperikan kepercayaan, apresiasi, dan kehormatan.

\section{Kelima: Berakhlak Guru}

Berakhlak guru merupakan karakteristik guru Nahdlatul Wathan dalam Wasiat Renungan Masa (Madjid, 2016). Berakhlak guru berarti berbuat, bertutur kata, dan berpikir sesuai adab seorang guru yang telah diajarkan oleh ulama' salaf. Penulis memandang bahwa akhlak guru dalam tradisi pendidikan Nahdlatul Wathan diadaptasi dari sejumlah kitab akhlak. Ada tiga kitab akhlak yang diajarkan di madrasah-madrasah Nahdlatul Wathan. Ketiga kitab tersebut adalah

Jurnal At-Tafkir: Volume 13 Nomor 1 Tahun 2020

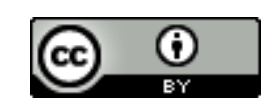

This work is licensed under a Creative Commons Attribution 4.0 International License 
al-Akhlāq li al-Banīn/al-Banāt, Ta'līm al-Muta'allim, dan Izhāh al-Nāshi'̄̄n (Usman, 2015).

Namun bagaimana pun, dari ketiga kitab yang dikaji, Ta'līm al-Mut'allim merupakan kitab akhlak yang paling dekat dengan dunia pendidikan. Dari judulnya, Ta'lim al-Muta'allim merepresentasikan isinya yang membahas adab dalam proses belajar-mengajar. Oleh karena itu dapat dikatakan bahwa standar moralitas pengajar dan pelajar dalam tradisi pendidikan Nahdlatul Wathan diadaptasi dari Ta'līm al-Muta'allim, yang dituangkan oleh Sheikh ke dalam beberapa wasiatnya, baik yang berhubungan dengan akhlak guru, murid, maupun relasi di antara keduanya.

Di samping itu, akhlak guru agama dalam tradisi pendidikan Nahdlatul Wathan dikayakan juga dengan mengadaptasi ajaran-ajaran tasawwuf. Hal tersebut dapat dilihat pada kurikulum keislaman yang diterapkan oleh perguruan tinggi non-formal Nahdlatul Wathan, yaitu Ma'had Darul Qur'an Wal Hadith alMajidiyyah al-Shāfi'yyah Nahdlatul Wathan (MDQH). MDQH merupakan ma'had 'aly yang setingkat strata satu (Sl), yang bertujuan untuk kaderisasi 'ulama', guru, dan muballig. Fahrurrozi (2019) menyebutkan bahwa program pengajian pendalaman tasawuf merupakan salah satu pelajaran yang masuk dalam kirukulum MDQH. Kitab tasawwuf yang dikaji adalah kitab Minhāj al'Ābidīn, karya Imam Al-Ghazali. Oleh karena itu ajaran-ajaran tasawuf al-Ghazali telah menjadi pengayaan nilai moral guru, dalam tradisi pendidikan Nahdlatul Wathan. Lebih dari itu tasawuf al-Ghazali merupakan ideologi tasawuf yang dianut oleh organisasi Nahdlatul Wathan.

\section{Keenam: Memiliki Silsilah Keilmuan Yang Jelas}

Memperhatikan silsilah keilmuan (sanad) sangat penting dalam perjalanan intelektual keislaman. Hal itu untuk memastikan bahwa ilmu keislaman yang didapat bersambung hingga para Sahabat kemudian Rasulullah. Sheikh misalnya mengibaratkan sanad seperti pipa air. Sumber airnya adalah Rasulullah dan para Sahabat, sedangkan pipa besarnya dimulai dari para tabi'in, terus kebawah. Semakin ke bawah, pipanya semakin mengecil. Sekalipun pipanya mengecil, hal itu tidak dianggap masalah. Yang penting adalah airnya mengalir dan kemurniannya terjaga (Rekaman Pidato Sheikh, tt.). Oleh karena itu, dalam tradisi pendidikan Nahdlatul Wathan, guru yang dipilih adalah guru yang tidak diragukan sanad keilmuan.

Tradisi memilih guru yang memiliki silsilah keilmuan yang jelas disebutkan pada bait ke-4, ke-183, dan 184 dalam wasiat Sheikh Zainuddin Abdul Madjid (2016). Memilih guru yang memiliki silsilah keilmuan adalah hal yang sangat urgen dalam menuntut ilmu. Guru agama bukan sekadar mengajar, membimbing dan mengayomi di dunia semata, namun lebih dari itu guru agama adalah imam menuju surga (Madjid, 2016). Oleh karena itu guru agama penting dipilih berdasarkan silsilah keilmuannya, agar bersambung hingga Rasulullah.

Dalam tradisi pendidikan Nahdlatul Wathan, ijazah ilmu, do'a, amalan, dan kitab-kitab turath merupakan cara untuk menyambung silsilah keilmuan

Jurnal At-Tafkir: Volume 13 Nomor 1 Tahun 2020

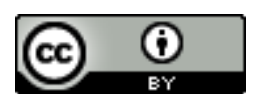

This work is licensed under a Creative Commons Attribution 4.0 International License 
dengan 'ulama' salaf, tābī' tābi'īn, tābī' tāb'î̀ tābi'īn dan seterusnya, hingga kepada sahabat kemudian Rasulullah. Menurut Fahrurrozi (2015) urgensi tradisi ijazah kitab di madrasah/pesantren Nahdlatul Wathan adalah, pertama sebagai bentuk tafā'ulan terhadap isi kitab yang dikaji di pesantren/madrasah, dengan harapan agar ilmu yang dikaji berkah dan dapat diamalkan; kedua, secara penanda silsilah keilmuan dari guru kepada murid; dan ketiga, untuk mempertegas geneologi keilmuan guru kepada muridnya, yang ditandai dengan proses ijazah dalam bentuk ijab dan qabul. Bahkan Nu'man \& Sahafari (1988) menyatakan bahwa salah satu bentuk kepribadian warga Nahdlatul Wathan adalah menerima do'a (ilmu) melalui proses ijazah.

Dalam tradisi sufi, ijazah lazim digunakan untuk dapat mengamalkan ajaran sebuah tarekat (țārīqah). Ijazah secara bahasa berarti membolehkan, sehingga ijazah mengandung maksud yaitu membolehkan orang yang menerima ijazah untuk mengamalkan ilmu yang diijazahkan, bahkan dapat diijazahkan kembali, setelah gurunya meninggal dunia. Hal tersebut menunjukkan bahwa menjaga kemurnian ilmu dengan memperhatikan sanad keilmuan guru sangat penting melalui akad intelektual yang dikenal sebagai ijazah.

\section{Ketujuh: Bijaksana dan Santun dalam Bertutur Kata}

Adab bertutur kata dalam bergaul banyak diungkapkan dalam al-Qur'an dan hadith. Ayat-ayat yang berkaitan dengan adab bertutur kata diungkapkan dengan banyak ungkapan dalam al-Qur'an.

Tabel 3: Ungkapan-Ungkapan Santun dalam al-Qur'an

\begin{tabular}{|c|c|}
\hline Qawlan layyina (ucapan yang lembut) & Tāha (20): 44 \\
\hline Qawlan sadida (ucapan yang benar) & $\begin{array}{l}\text { Al-Nisā' (4): } 9 \text { \& al-Aḥzāb } \\
\text { (23): } 70\end{array}$ \\
\hline Qawlan ma'rufa (ucapan yang baik) & $\begin{array}{l}\text { Al-Baqarah (2): 235, Al-Nisā' } \\
\text { (4): } 5 \& \text { \& al-Aḥāa (23): } 32\end{array}$ \\
\hline Qawlan karima (ucapan baik) & Al-Isrā' (17): 23 \\
\hline $\begin{array}{l}\text { Qawlan maisura (ungkapan yang mudah } \\
\text { dipahami) }\end{array}$ & Al-Isrā' (17): 28 \\
\hline Qaulan`azima (ungkapan yang hebat) & Al-Isrā' (17): 40 \\
\hline Qawlan baligha (ucapan yang indah) & Al-Nisā' (4): 63 \\
\hline
\end{tabular}

Ungkapan-ungkapan santun pad tabel 3 di atas, ditelusuri melalui kitab al-Mu'jam Mafahras li al-Alfāz al-Qur'an karya al-Bāqī (n.d.). Jika dianalisis, ungkapan-ungkapan tersebut merupakan ungkapan yang menyenangkan, membahagiakan dan memotivasi. Cara bertutur inilah yang diperlukan dalam pergaulan manusia, lebih-lebih pergaulan antara guru dan murid. Al-Ghazali bahkan mengatakan bahwa murid itu

Jurnal At-Tafkir: Volume 13 Nomor 1 Tahun 2020

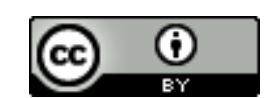

This work is licensed under a Creative Commons Attribution 4.0 International License 
Dalam bertutur kata, guru harus menghindari sikap mengejek, menghardik, dan melakukan perundungan (bullying) terhadap pelajar. Hal tersebut berdampak positif bagi siswa. Siswa akan menunjukan sikap simpati dan tergugah untuk menyukai apa yang disampaikan oleh gurunya (al-Māwardī, 2013). Ketika guru berkomunikasi dengan muridnya, maka guru harus menghindari secara verbal dan nonverbal ungkapan-ungkapan yang dapat menyakiti muridnya, baik secara fisik maupun secara psikis.

Karakteristik guru yang bermoral tidak hanya ditunjukkan oleh perbuatan, namun juga ditunjukkan oleh ucapan yang bijaksana dan santun. Sheikh Zainuddin Abdul Madjid (2016) berkata:

"Aduh sayang

Arif bijaksana jadikan guru

Tutur sapanya baik selalu

Gerak-geriknya patut ditiru

Tukang tidak membuang kayu"

Sheikh menegaskan bahwa sikap arif, bijaksana, dan santun dalam bertutur diharapkan memberikan pengaruh positif kepada para pelajar. Para pelajar dapat mencontoh kebaikan-kebaikan gurunya dalam berucap. Dalam pepatah Nusantara dikatakan bahwa guru itu digugu dan ditiru. Guru dalam hal ini menjadi role model bagi anak didiknya. Setiap tingkah laku dan tutur katanya tidak lepas dari pengamatan anak didiknya. Tingkah laku dan perkataan guru diamati, direkam, dan diperagakan.

\section{Kedelapan: Kompeten}

Kompetensi merupakan merupakan kata serapan dari kata competence yang berarti kemampuan untuk melakukan sesuatu dengan baik, sedangkan kompeten adalah yang memiliki kemampuan atau pengetahuan yang cukup untuk melakukan pekerjaan dengan baik atau untuk memenuhi standar kewajiban (Hornby, 2000). Guru yang kompeten berarti guru yang memiliki kemampuan dan pengetahuan yang memadai dalam menjalankan aktivitas belajar-mengajar. Tanpa kompetensi yang memadai, dapat dipastikan proses pembelajaran menjadi terhambat. Oleh karena itu, guru penting dipilih dari aspek kemahirannya, termasuk guru dalam bidang keislaman.

Dalam tradisi Nahdlatul Wathan, Sheikh sangat menekankan pemilihan guru berdasarkan keahliannya. Hal itu disebut berulang kali dalam salah satu karya Sheikh dalam ilmu tajwid, yang berjudul Batu Ngompal sebagai berikut:

\section{(1)}

Belajar olehmu tajwid yang sahih karena Qu'an turunnya fasih Jangan membaca bacaan qabih takut ancaman hadith yang sahih Rajin berguru pada ahlinya (3)
(2)

Baca olehmu bacaan Jibrila jangan membaca bermain gila Firman Ilahi di dalam Tanzila Warattilil Qur'ana tartila Rajin berguru pada ahlinya

Jurnal At-Tafkir: Volume 13 Nomor 1 Tahun 2020

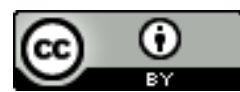

This work is licensed under a Creative Commons Attribution 4.0 International License 
Jaranglah pandai membaca Qur'an

Kebanyakan asyik tidak karuan

Malu berguru tajwidnya Qur'an

Besar kepala takut teguran

Rajin berguru pada ahlinya
Ayo hai saudara, ayo hai saudari

Tuntutlah ilmu setiap hari

Jangan bermegah ke sana ke mari

Agar selamat belakang hari

Rajin berguru pada ahlinya (Madjid, n.d.)

Ahli berarti tidak sekadar memiliki ilmu pengetahuan, namun memiliki kemampuan memadai, yang dapat ditinjau dari empat aspek, yaitu; pedagogik, kepribadian, sosial, dan profesional. Kemampuan pedagogik berarti guru memiliki kemampuan mengajar. Guru memiliki pengetahuan dan kemampuan mentransfer pengetahuan kepada murid-muridnya. Kompetensi kepribadian berarti guru memiliki kepribadian yang baik. Secara umum, guru mampu mengelola emosinya dengan baik. Kompetensi sosial menghendaki guru untuk dapat bersosialisasi sesuai dengan norma-norma yang berlaku, baik norma agama maupun adat istiadat dan kearifan lokal di mana guru mengajar. Kompetensi profesional menuntut guru untuk menguasai materi yang diajarkan secara luas serta dapat melakukan pembimbingan kepada murid-muridnya.

Dari keempat kompetensi tersebut, (Al-Zarnūjīi, 1981) hanya menekankan pada dua kompetensi yaitu profesional dan kepribadian, sebagaimana yang dapat dilihat dalam ungkapan berikut:

$$
\text { أما اختيار الأستاذ فينبخي أن يختار الأعلم و الأورع و الأسن... }
$$

Kata al-a'lam (orang yang paling tahu) dalam ungkapan al-Zarnūji tersebut menunjukkan arti professional, yaitu guru yang dipilih memiliki wawasan dan pengalaman yang luas. Professional berarti ahli di bidangnya. Adapun kata alawra' (orang yang paling tindih) menunjukkan bahwa guru harus memiliki kompetensi kepribadian yang baik. Kedua kompetensi tersebut dapat dikatakan sebagai kompetensi dasar yang harus dimiliki setiap guru.

Dalam sebuah penelitian komparatif disebutkan bahwa tidak kurang dari tujuh kompetensi kepribadian guru di dalam kitab Ta'lim al-Muta'allim. Ketujuh kompetensi tersebut adalah al-a'lam (lebih berpengetahuan), al-awra' (lebih menjaga), al-asanna (berpengalaman atau lebih tua), berwibawa, al-ḥilm (santun) dan sabar. Adapun di dalam kitab Adab al-'Alim wa al-Muta'allim karya KH. Hasyim Asy'ari, disebutkan ada 10 kompetensi kepribadian seorang guru. Kesepuluh kompetensi tersebut adalah takwa kepada Allah, semangat, berakhlak mulia baik terhadap diri sendiri maupun terhadap orang lain, wara', ikhlas, adil dan jujur, tekun dan disiplin, serta teladan (Muntachobat, N., Mansur, R., \& Lismanda, 2019).

\section{Kesembilan: Istiqamah}

Istiqamah secara bahasa berarti tegak dan lurus dalam ketaatan kepada Allah (Manẓūr, n.d.). Istiqamah merupakan garis yang bagian-bagian pokoknya sejajar antara yang satu dengan yang lainnya dalam segala keadaan. Di kalangan sufi, ikhlas dipahami sebagai menepati seluruh janji dan senantiasa di jalan yang

Jurnal At-Tafkir: Volume 13 Nomor 1 Tahun 2020

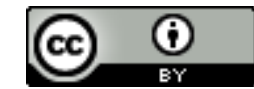

This work is licensed under a Creative Commons Attribution 4.0 International License 
lurus dengan memperhatikan sikap tawassut dalam segala hal, seperti makan, minum, berpakaian, dan semua urusan agama dan dunia. Istiqamah juga berarti mengumpulkan antara melaksanakan ketaatan dan menjauhi kemaksiatan. Istiqamah juga dianggap lawan dari kata bengkok, yang berarti bahwa perjalanan seorang hamba di jalan ibadah dengan petunjuk syariat dan akal (al-Jurjāni, n.d.). Oleh karena itu, guru yang istiqamah adalah guru yang selalu aktif mendedikasikan hidupnya di jalan yang lurus dengan penuh ketaatan, baik kepada Allah, Rasulullah, maupun ulul amri.

Dalam perspektik tasawuf, istiqamah merupakan derajat kesempurnaan dari semua usaha. Eksistensi istiqamah dalam diri seseorang mendatangkan kebaikan. Meninggalkan sikap istiqamah, berarti menyia-nyiakan kesempatan dan semua yang telah diusahakan. Seseorang yang meninggalkan sikap istiqamah berarti posisinya tidak akan pernah naik (stagnan), sehingga perilakunya menjadi tidak sehat (al-Qushayri, 2001). Hal tersebut menunjukan bahwa menguatkan sikap istiqamah dapat memberi dampak positif. Sikap istiqamah ibaratnya prosedur akhir dari segala perbuatan baik. Ketika perbuatan baik dilaksanakan, maka proses selanjutnya adalah kontinuitas atau keberlanjutan (istiqamah), untuk mendapatkan hasil yang sempurna.

Dalam konteks pendidikan Nahdlatul Wathan, sikap istiqamah merupakan salah satu nilai operasional pendidikan Nahdlatul Wathan(Usman, 2015). Selain istiqamah, yakin dan ikhlas merupakan nilai perjuangan Nahdlatul Wathan. Yakin, ikhlas, dan istiqamah merupakan pilar-pilar strategis untuk menjaga visi fundamental Nahdlatul Wathan yaitu iman dan takwa (Usman, 2015).

Istiqamah dalam tradisi Nahdlatul berarti tetap berada di jalan kebenaran dan kebaikan untuk berjuang melalui pendidikan. Sikap istiqamah dalam pendidikan dapat diaktualisasikan melalui sikap disiplin guru. Guru selalu hadir ke madrasah sesuai dengan jadwal yang ditetapkan. Jika diberikan tugas, guru yang istiqamah akan melakukan dengan sepenuh hati. Tradisi-tradisi pendidikan agama yang baik aktif dilakukan. Guru yang istiqamah selalu menampakkan semangatnya dalam membimging siswanya-siswanya.

\section{KESIMPULAN}

Sebagaimana tujuan dari penelitian ini adalah untuk mengetahui dan memahami karaktersitik guru dalam tradisi pendidikan Nahdlatul Wathan, maka penelitian ini menunjukkan bahwa ada sembilan karakteristik yang harus dimiliki oleh guru agama dalam tradisi pendidikan Nahdlatul Wathan, yaitu: pertama, murshid, yaitu guru yang menunjukkan dan menuntun muridnya ke jalan yang benar; kedua, ikhlas, yaitu menjalankan aktivitas pengajaran, pembimbingan, dan pengayoman tanpa pamrih, dan tidak mengharap balasan baik harta maupun pujian; ketiga, taat, yaitu tunduk dan patuh dalam keataatan kepada Allah, Rasulullah, dan ulil amri yang meliputi pemerintah, pimpinan organisasi Nahdlatul Wathan, guru, dan kedua orang tua;

Jurnal At-Tafkir: Volume 13 Nomor 1 Tahun 2020

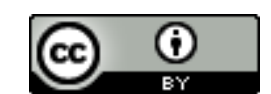

This work is licensed under a Creative Commons Attribution 4.0 International License 
Keempat, amanat, bersikap bertanggung jawab baik di dalam maupun di luar sekolah; kelima, berakhlak guru, artinya berakhlak sebagaimana adab guru dalam ajaran Ta'lim al-Muta'allim, tasawuf al-Ghazali, dan Wasiat Renungan Masa; keenam, memiliki silsilah keilmuan yang jelas, yaitu guru yang layak dipilih adalah guru yang bersambung sanad keilmuannya hingga Sahabat dan Rasulullah;

Ketujuh, bijaksana dan santun dalam bertutur kata; kedelapan, kompeten, yaitu guru yang memiliki keahlian dan kemampuan yang mumpuni minimal pada aspek kepribadian dan profesional; dan kesembilan, istiqamah, yaitu tetap berjalan di atas kebenaran dan kebaikan untuk berjuang melalui jalur pendidikan. Penelitian ini menyimpulkan bahwa karakteristik-karakteristik guru yang disebutkan di dalam wasiat Sheikh didasari oleh hasil perenungan (tafakkur), pengalaman empiris (tajrïbah), dan ilmu pengetahuan yang luas.

\section{DAFTAR PUSTAKA}

Daradjat, Z. (2016). Ilmu Pendidikan Islam. Jakarta: Bumi Aksara.

Madjid, M. Z. A. (2016). Batu Ngompal. Lombok Timur: Pengurus Besar Nahdlatul Wathan.

Madjid, M. Z. A. (n.d.). Batu Ngompal. Lombok: Pengurus Besar Nahdlatul Wathan.

Al-Zarnūjīi, B. D. (1981). Ta'līmu l-Muta'llim fi Ṭuruqi t-Ta'allumi (M. Qabbāni, ed.). Beirut: Al-Maktab al-Islāmī.

Jama'ah, I. (2012). Tadhkiratu al-Sāmi' wa al-Mutakallim fi Adabi al-'Ālim wa al-Muta'llim

(M. M. Al-'Ajmi, ed.). Beirut: Shirkah Dār al-Bashā'ir al-Islamiyyah.

al-Ghazali, A. H. M. bin M. (2005). Ihyā' Ulūm al-Dīn. Beirut: Dar Ibn Hazm.

al-Jurjāni. (n.d.). Mu'jam al-Ta'rifat (Muhammad Sadiq al-Minshāwī, ed.). Kairo: Dār al-Faḍilah.

Sayyi, A. (2017). Wasiat Pendidikan Sufistik Dalam Naskah Tanbih Mursyid

Tarekat Qodiriyyah Naqsyabandiyah Suryalaya ( Telaah Pemikiran Guru

Mursyid Tqn Suryalaya). Fikrotuna, 5(1).

https://doi.org/https://doi.org/10.32806/jf.v5il.2947

Atjeh, A. (1985). Pengantar Ilmu Tarekat. Solo: CV. Ramadhani.

'Ulwān, A. N. (1976). Tarbiyat al-Awlād fi al-Islām. Jeddah: Dar al-Salām li al-

Tabā'ah wa al-Nash wa al-Tawzī'.

al-Bustānī, M. B. (1987). Muḥịt al-Muhīṭ: Qamūs Mutawwal li al-Lughah al-'Arabiyyah

(Maktabah Lubnān, ed.). Beirut.

al-Qushayri. (2001). Al-Risalat al-Qushayriyyah. Beirut: Dār al-Kutub al-'Ilmiyyah.

Usman. (2015). Pedagogik Nahdlatul Wathan: Isi, Metode, dan Nilai. Mataram: LEPPIM IAIN Mataram.

Manẓūr, I. (n.d.). Lisān al-'Arab. Kairo: Dār al-Ma’ārif.

Munawwir, A. W. (1984). Kamus Arab-Indonesia al-Munawwir. Surabaya: Pustaka Progresif.

Jurnal At-Tafkir: Volume 13 Nomor 1 Tahun 2020

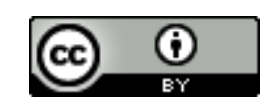

This work is licensed under a Creative Commons Attribution 4.0 International License 
al-Bāqīi, M. F. A. (n.d.). al-Mu'jam al-Mafahras li al-Fāz al-Qur'ān al-Karīm. Kairo: Mațba'ah Dār al-Kutub al-Mișriyyah.

Kathīr, I. (1997). Tafsīr al-Qur'ān al-'Aż̄m. Beirut: Dār al-Kutub al-'Ilmiyyah.

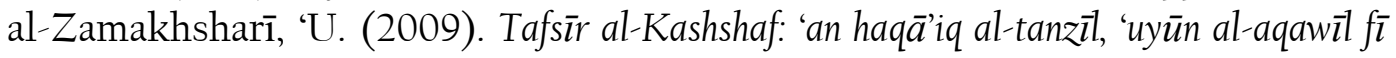
wujūh al-ta'wīl. Beirut: Dār al-Ma'rifah.

al-Maydāni, A. R. H.. J. (1995). Rawā'I min Aqwāl al-Rasūl. Damaskus: Dār al-Qalam. al-Hajjājīi, H. (1977). al-Fikr al-Tarbawì 'inda Ibn al-Qayyim. Jeddah: Dār Hāfiz li alNashr wa al-Tawzì'.

Ali, M. H. (1977). al-Tarbiyyah al-Islamiyyah min Khilal al-Qur'an al-Karim wa al-Sunnah al-Nabawiyyah. Yarusalem al-Quds: Dar al-Tiba'ah al-'Arabiyyah.

Fahrurrozi. (2019). Nahdlatul Wathan: Refleksi keislaman, kebangsaan dan keummatan. Mataram: CV. Al-Haramain Lombok.

Fahrurrozi. (2015). Tuan Guru: Eksistensi dan tantangan peran dalam transformasi masyarakat. Jakarta: Sanabil.

Nu'man, A. H., \& Sahafari, A. (1988). Nahdlatul Wathan: Organisasi pendidikan, sosial dan dakwah. Lombok Timur: Pengurus Daerah Nahdlatul Wathan Lombok Timur.

al-Māwardī. (2013). Adab al-Dīn wa al-Dunyā. Beirut: Dār al-Minhāj.

Hornby, A. S. (2000). Oxford Advanced Learner's Dictionary od Current English (6th ed.). Oxford: Oxford University Press.

Muntachobat, N., Mansur, R., \& Lismanda, Y. F. (2019). Konsep Kompetensi Kepribadian Guru Pendidikan Agama Islam (Tela'ah Kitab Ta'lim AlMuta'allim Karya Az-Zarnuji dan Kitab Adab Al-'Alim Wa Al-Muta'allim Karya KH. Hasyim Asy'ari). VICRATINA: Jurnal Pendidikan Islam Volume, 4(4856).

\section{Internet}

https://akurat.co/news/id-835557-read-kpai-17-kasus-pelecehan-seksual-disekolah-didominasi-jenjang-sekolah-dasar

https://kumparan.com/kumparannews/mayoritas-pelaku-kekerasan-seksualpada-anak-di-sekolah-adalah-guru-lsPVphddxKE https://kompas.id/baca/nusantara/2019/07/11/15-santri-di-aceh-jadi-korbanpelecehan-seksual// https://www.ajnn.net/news/penangguhan-penahanan-ditolak-ini-respon-kuasahukum-tersangka-pelecehan-seksual/index.html 